WellBeing International

WBI Studies Repository

2007

\title{
Naturalizing Anthropomorphism: Behavioral Prompts to Our Humanizing of Animals
}

\author{
Alexandra C. Horowitz \\ Barnard College \\ Marc Bekoff \\ University of Colorado
}

Follow this and additional works at: https://www.wellbeingintlstudiesrepository.org/acwp_habr

Part of the Animal Studies Commons, Comparative Psychology Commons, and the Other Anthropology Commons

\section{Recommended Citation}

Horowitz, A. C., \& Bekoff, M. (2007). Naturalizing anthropomorphism: Behavioral prompts to our humanizing of animals. Anthrozoös, 20(1), 23-35.

This material is brought to you for free and open access by WellBeing International. It has been accepted for inclusion by an authorized administrator of the WBI Studies Repository. For more information, please contact wbisr-info@wellbeingintl.org.

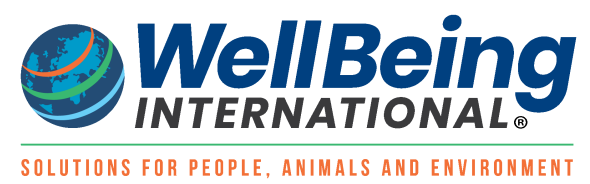




\title{
Naturalizing Anthropomorphism: Behavioral Prompts to Our Humanizing of Animals
}

\author{
Alexandra C. Horowitz ${ }^{1}$ and Marc Bekoff ${ }^{2}$ \\ ${ }^{1}$ Barnard College \\ ${ }^{2}$ University of Colorado - Boulder
}

\section{KEYWORDS}

anthropomorphism, attention, cognitive ethology, dogs, humanizing animals, social play

\begin{abstract}
$\underline{\text { ABSTRACT }}$
Anthropomorphism is the use of human characteristics to describe or explain nonhuman animals. In the present paper, we propose a model for a unified study of such anthropomorphizing. We bring together previously disparate accounts of why and how we anthropomorphize and suggest a means to analyze anthropomorphizing behavior itself. We introduce an analysis of bouts of dyadic play between humans and a heavily anthropomorphized animal, the domestic dog. Four distinct patterns of social interaction recur in successful dog-human play: directed responses by one player to the other, indications of intent, mutual behaviors, and contingent activity. These findings serve as a preliminary answer to the question, "What behaviors prompt anthropomorphisms?" An analysis of anthropomorphizing is potentially useful in establishing a scientific basis for this behavior, in explaining its endurance, in the design of "lifelike" robots, and in the analysis of human interaction. Finally, the relevance of this developing scientific area to contemporary debates about anthropomorphizing behavior is discussed.
\end{abstract}

\section{What Causes us to Anthropomorphize?}

In studies of animal behavior, there is near official consensus about anthropomorphizing: it is to be avoided. While the term anthropomorphism literally refers to the characterization of nonhuman behavior or inanimate objects in human terms, it has been further appropriated to refer to such characterization specifically when it is erroneous. In particular, an attribution which is not only unproven, but which is considered unlikely, is an anthropomorphism: the explanation of the cock of a parrot's head as evidence of his puzzlement; the easy assignment by a pet owner of love and desire to her dog. It is taken to be just those characteristics we attribute to a subject that the subject does not have (Asquith 1984).

Significantly, anthropomorphism, despite its accepted status as a fundamentally flawed way to describe nonhuman animal behavior, has long endured, both within the scientific community and especially in the 
general public's conception of animals. Among lay people, anthropomorphism is not only prevalent, it is the nearly exclusive method for describing, explaining, and predicting animal behavior-whether the animals are kept as pets, visited in the zoo, or observed in nature.

The strong tendency to use human terms to describe animal behavior has prompted some to ask why we anthropomorphize at all (Caporael and Heyes 1997). The behavior and causes of anthropomorphizing have not been the subject of systematic analysis (Guthrie 1997). In the present paper, we begin to remedy this with an initial analysis of the behaviors of social play between dogs and humans. In particular, we ask: What behaviors by dogs in play correspond to the behavior of projective anthropomorphizing by owners? By looking at the context of this class of anthropomorphisms, the relevant attributional stances can be reduced to a few behavioral cues. Such an analysis may be informative not only about the subjects of the attributions, but also about the attributers.

In this paper, we begin with the precedents to a study of anthropomorphizing; then we apply its method to behavioral data of dog-human play. We propose to use ethology as a model for the study of the behavior. To this analysis we add prior accounts of the prompts for anthropomorphism from various sources: robotics, social science, and ethology. Finally, we consider the relevance of an analysis of anthropomorphizing to traditional discussions of anthropomorphisms in science.

\section{An Ethological Approach to Anthropomorphism}

The science of ethology provides a methodology for considering anthropomorphizing behavior analytically. Ethology is the study of animal behavior in natural settings, using live observations and videotapes to record data of focal behaviors or subjects, transcription of the recorded events in an inventory of behavioral units coded per an ethogram, and analysis of behavior patterns. We propose that data of use of anthropomorphisms will show that they are reliable and identifiable enough that they may themselves be treated ethologically. Just as the observational method of ethology has provided a means to naturalize sociality, aggression, communication, theory of mind, and many other phenomena by tying these concepts to seen behaviors, the attributions humans make to animals can be characterized and correlated with seen behaviors through ethological methods.

By examining both general and specific application of anthropomorphisms, a catalogue of physical and behavioral features which lead to anthropomorphizing behavior in humans could be formed. This method may yield results with application to the design of lifelike robots, and lead to a clearer understanding of humans'-scientist and lay alike —-tendency to anthropomorphize.

Theoretical precedent for this approach comes from the comparative psychologist Donald Hebb. In his time at Yerkes, he noted that in contrast to his own non-attributive description of the captive chimpanzees' behaviors, the keepers' anthropomorphic accounts provided a useful guide to the behavior of their charges (Hebb 1946). Rather than working to eliminate anthropomorphisms outright, Hebb and the other researchers recorded the behavior patterns of the animals alongside their anthropomorphic glosses. In particular, they specified those behavior patterns that led to the attribution of emotions such as fear, nervousness, and shyness. This yielded a psychological description of animal behavior (Mitchell and Hamm 1996).

Even though Hebb did not see it as a study of anthropomorphism per se, his results support the theory that anthropomorphizing is a well-defined class of behaviors that has clear manifestations, clear triggers, and evaluative usefulness. We have appropriated and refined Hebb's method for our present ethological analysis. Such analyses seem to be gaining momentum, as presaged by Mitchell and Thompson's (1986a) discussion of the viability of investigating which "biological and psychological processes" lead to 
the attribution of deception in nonhuman animals. Three studies have looked at subjects' reports of what is "going on" in a film playback: of moving shapes (Heider and Simmel 1944; Berry et al. 1992) and of dogs interacting with their caregivers (Morris, Fidler and Costall 2000). Of these, Berry et al. looked to identify the properties of stimuli that give rise to distinct anthropomorphisms; Morris, Fidler and Costall found that subject reports were consistent, anthropomorphic, and were reliably matched to episodes of behavior, distinct "event units." We present a complementary approach: identifying the repeated behavior patterns in just those bouts of play which the (human) participants identified as "successful" or "satisfying," and expressed that their dogs understood or enjoyed the play.

\section{Anthropomorphisms in Dog-Human Play}

In just what circumstances are anthropomorphisms made? We use the ethological data of interaction between the anthropomorphizers-humans-and the anthropomorphized-dogs-to discover regularities in the human attributions. The result is a preliminary catalogue of the behaviors that correspond to one kind of anthropomorphizing - the attribution of playful intent or understanding-by humans engaged in dyadic play with their dogs. In this paper, we focus on the proximal causes of anthropomorphism; further research might explore the evolutionary or predictive uses thereof.

The data from which this analysis draws are the result of research done to advance the design of a petlike robot, Sony's "Aibo." In 2003 one of us (A.H.) performed an observational study of dog-human interactions in play to create a catalogue of play behaviors (more details of the methods of this study are available elsewhere ${ }^{1}$ ). One goal in the design of the Aibo robot is to "encourage human and robot interaction" (Sony entertainment robot Aibo operating instructions 2000). The robot is dog-like in its form-it is four-legged, has a tail, characteristic head form, etcetera-and behavior-it ambles and wags like a dog, barks, and performs simple trained-dog routines-and is intended to interact with human beings. The research was motivated by a desire to create play routines and games which could be modeled in a dog-like robot such as Aibo. With this method, what initially appear to be highly complex social interactions can be deconstructed, and then reconstructed in the robot.

The data also capture a variety of the ways that humans interact with, and the expectations they have of, a creature which holds special status in American culture: the domestic dog. Dogs are distinguished not only by being one of the only animals granted access inside the homes and families of a majority of the population (U.S. Pet Ownership Statistics 2006) - they also are particularly subjected to our tendency to anthropomorphize. The plethora of books published annually on the subject of dog-ownership tread easily and without controversy on the topics of peoples' "relationships" with dogs, the animals' "understanding" and "love;" what dogs "know," "like," "think about;" dogs who are "shy," "trying to tell you" something, who have a "point of view;" who experience "grief" and "friendship." They are fitting subjects for a new examination of why we anthropomorphize.

This study of dog-human play behavior is part of the growing field of study of dog-human interaction (Sanders 1999; Podberscek, Paul and Serpell 2000; Irvine 2004) and of cognitive phenomena in doghuman play in particular (Mitchell and Thompson 1986b; Mitchell and Thompson 1991; Rooney, Bradshaw and Robinson 2001). Following the ethological methods of these and other studies of social play (e.g., Tomasello et al. 1994; Bekoff and Byers 1998; Horowitz 2002), in this research videos were taken of humans interacting in a self-described playful way with their own dogs. For these purposes, "play" — which, though easy to recognize, is more difficult to characterize (Bekoff and Byers 1998)—was defined as voluntary, coordinated behavior between a human and a dog which often followed a routine form (characterized below). A play bout was considered complete if the episode included identified play behaviors (Horowitz 2002) and lasted for two or more turns on each participant's part. The "routines" (Mitchell and Thompson 1986b) seen included object retrieval games (fetch: throw, retrieval, and 
sometimes pursuit); object possession games (tug-of-war; keep-away); social playmate games (chase); feigning games (wrestling; growling; vocalizing); and parallel behavior (running alongside one another; mutual posture-changing). Play occurred naturally, and was not manipulated by the observer. Play bouts took place and were recorded in public settings-the majority in Central Park, New York City, and enclosed parks designated "dog parks" in the city.

The data from this study can be appropriated to consider the behavioral correlates of anthropomorphism. In post-play questionnaires and in volunteered concurrent commentary, the human players often projected psychological states onto the animals: their dogs "understood" the game and "know" what they were "supposed to do;" the dogs were playing "fair," being "cooperative" or "sneaky," or were trying to "trick" their partner; their dogs "like" playing with them; they were "having fun," and "loving it." These descriptions occurred during or after "successful" play, as per the owners' assertions that the play had gone well. They were thereby distinguished from those in which the human players expressed frustration or abandoned the bout prematurely. Fifteen (15) independent "successful" sessions of dogs interacting with their human caretakers in object retrieval, object possession, and feigning games were selected for analysis. Insofar as the estimations of the dogs' psychological states are unproven (by the owners and by behavioral scientists), they can fairly be called "anthropomorphisms." The analyzed bouts serve as the medium for anthropomorphisms of playful intention or understanding.

Examination of the ethological record of behaviors of these play bouts, supplemented with data from behavioral analysis of dyadic dog play (Horowitz 2002), reveals distinctive patterns in the interaction between players.

\section{Categories of Social Behavior}

From the catalogue of dog and human behaviors across play bouts, we have identified numerous behaviors that repeat in successful bouts-and that are often absent in unsuccessful bouts or when play collapses. These examples suggest a grouping based on their commonalties. Four "social categories"distinct groups of behaviors or patterns of behavior which expose and represent a feature of social interaction-are introduced below. Capsule summaries of some of the exemplar behavior patterns noted across play sessions follow.

(1) Directed responses to the other: A characteristic phenomenon of play bouts is each player's regular and reliable responsiveness to the other player: a sort of verification of the other's participation in the dialogue. This is particularly manifested by the use of the attention of the other player. A coordinated use of attention appears to be integral to play (Tomasello et al. 1994; Horowitz 2002). Every successful doghuman bout had some example of this. For instance, in this study, games often began with full-face contact between the human and the dog: each oriented his face to the other's face. In some instances, this contact was additionally seen as the game unfolded. In a typical game of fetch, for example, every time the ball was returned to the owner, the human player paused until they shared eye or face contact before throwing the ball again. In the same way, by orienting one's face away from the other's, a play session may be ended.

Successful bouts had examples not just of such gaze-holding, but also of gaze-monitoring, such as gaze alternation in play involving an object. During gaze alternation the dog looks at the object, looks at the face of his human playmate, and looks back at the object, in quick succession, repeatedly over the course of a few seconds. This behavior appears to draw the human into the game. Similarly, "checking"-looking back at the face of, especially, a non-responding human-is frequently seen. Even accidental behaviors can serve to perpetuate the sense of a dialogue, such as in one case of a dog who dropped a ball prematurely and then immediately looked to the face of her owner. 
Another form of directed response to the other player is seen in the maintenance of a social distance appropriate to the players and to the game. Dogs and humans in play maintain a consistent distance from each other in each stage of play. There are seeming "rules" of social distance, with different rules for different games. (The distance between players appears to be established by each dyad.) Violation of the social distance rules often leads to an abrupt end of play. Interestingly, dogs seem to be able to manipulate the fact of these implicit rules to indicate when they are finished playing. As an example, in "fetch" one must reliably bring the fetched object to within a retrievable distance of the thrower. The game can be ended by broaching this play boundary: in ethological terms, either by maintaining distance and not returning the ball, or by getting overly close, and engaging in a distinct social activity (such as begging or presenting oneself for affection). In "keep-away," one must pass just outside of approximately one body-length of a human. The game ends when caught-i.e., when the human can reach the dog.

Behavior patterns that function as lures for social interaction also come under this heading. Those animals that solicit attention, instead of simply reacting to attention, evoke particular interest. Anecdotes from the robotics community indicate the persuasiveness of preemptive attention, such as the delighted response of a passerby as a robot monitored and reached out to touch him as he approached (Ishiguro 2003). The domestic dogs of this study used two lures: an approach (to an attending human) accompanied by a wagging tail; and reaction to the divided attention of the human by changing posture (as from a seated posture to standing, or from standing to approaching).

What is similar and salient in all these examples is that human attention changes the dog in some way: the dog responds directly to the attentional posture of another.

(2) Indications of intent: Another grouping can be made of behavior patterns which have in common a use to indicate intent to play or to act within play: in non-mentalistic terms, the behaviors are reliably associated with action patterns that immediately follow. Intent is expressed through various communicatory and showing behaviors. For instance, in many bouts, dogs barked until a human began a game (as when a human was in possession of, but not tossing or relinquishing, a ball for play). Barking prior to play signaling is seen to work as an attention-getter in dog-dog social play (Horowitz 2002). Likewise, humans vocalized to start games, despite the fact that they were communicating to non-verbal recipients. In a typical instance, one human player repeated, "ready, go!" with each toss of the ball to her dog. Vocalizations by both participants are thus used as attention-getters and also to mark the start of play or a play cycle.

Almost all play bouts that involved the use of an object—a toy or ball—began with "showing:" either the dog or the human presented the object in front of the other's face or body. Similarly, when not playing with objects, each participant can begin play by presenting oneself: orienting one's body so as to be directly in the line of sight of the other, at a proximate distance.

The bouts reveal many other behaviors that reliably indicate readiness to play or correspond to the beginning of play. These include a paw or hand slap (slapping both hands or front paws on the ground) (Bekoff 1972); tail-wagging; holding ears erect; tilting one's head (dog only); and holding a frozen posture (as a crouch, in humans) often with one's mouth slightly open. Many of these behaviors are identified "play signals" in nonhuman social play (Garvey 1976; Fagen 1981; Tomasello et al. 1994; Horowitz 2002; Bekoff 2004).

(3) Mutuality: Many play behaviors serve as expressions of a shared engagement: of the recognition of being engaged in the same activity as the other player. Play among animals is typified by a coordination and integration befitting a human conversation: each participant must react dynamically to the actions of the other (Bekoff 2004; Horowitz 2004). 
The observed human-dog dyads showed several notable coordinated behaviors in play. Many bouts were remarkably similar in one regard: in each, the participants exhibited mirroring behavior. For instance, in response to a lunge by a human, a dog lunges; each grabs a toy in turn; after a human play-slaps, a dog play-bows. These behaviors are nearly absent in play bouts which collapse (Horowitz 2002); as such, they can be described as serving to incite or maintain play. Synchronized movements come under this rubric: running alongside one another, for instance. At some level, both interactants are acting togetherresponding to each other as if with a compatible set of assumptions about the activity, even if seeming to act at cross-purposes (Mitchell and Thompson 1986b).

(4) Contingent activity: ${ }^{2}$ Another aspect suggested by the observed behavior patterns is the importance of dependent activity: each player's actions are based on, and related to, what the other player has just done. This establishes a rhythm to the play. Such responsiveness is easily seen in human social interaction. Salience of coordination of behavior-as facial expressions-is already clear in mother-infant relations when the child is only two months old (Trevarthen 1979). In play, timing between players is critical to the success of the bout. A defining characteristic of social play is turn-taking (for discussion see, e.g., Garvey 1976; Fagen 1981; Horowitz 2002; Bekoff 2004; and references therein). The observed bouts provide examples of this phenomenon in two ways: in timing and in regularly alternating actions. The latter appears as turn-taking, though strict alternation of turns is not necessary. However, turns must be taken promptly, or the bout begins to disintegrate-requiring effort to be resumed, or ending outright. If a dog does not return directly with his ball, or a human gives chase but does not let himself be chased, play breaks down. The game ends if there is not a timely response by one's playmate. In this way, each player is responsible for helping to maintain the mutual excitement of play. In other words, the taking and timing of turns is non-trivial. Similarly, it may be that there are specific time frames required to evoke anthropomorphic reactions. Initial videotape observations reveal that in these anthropomorphized bouts, the subject dogs responded to a ball leaving a thrower's hand (or to a gestured intent to throw-a kind of "intention movement") in as little as five frames (approximately one-sixth of a second). Mirroring responses by each to the other's behavior-a lunge, for instance-are much slower, but often occur in under one second.

Each social category includes behaviors that are central to the success of the interaction between the observed players, and each game is composed of some of these elements. For instance, "fetch," a typical dog-human game in which the human tosses a ball for the dog's retrieval, goes smoothly when many of these components are present: the dog or the human gets the attention of the other (category 1); a human indicates an intent to throw the ball (2), a dog expresses reactive readiness (3); there is mutual turn-taking (4); and a dog returns to a human-defined distance in a human-scale time (1 and 4). There is a kind of "dialogue" which includes attempts to engage, feedback, turn-taking, and routines. "He gets it," one owner smiled at his dog following a rousing, uninterrupted bout of fetch.

Thus, examination of the videotaped episodes of dog-human play allows us to identify elements that correspond to these owners' impression that both players were full participants in the interaction. These social categories capture the behaviors which were repeated when the human player expressed the sentiment that his dog had experiences or emotions about playing which resembled his own. The behaviors include: the violation or following of rules; recognition of and concession to the other player; appreciation of the other's role in the game; behavioral evidence of shared engagement; and sensitivity to the other player. The identification of these components of successful play is in effect an identification of those elements of the animals' behavior which lead humans to attribute understanding to them. In this way, the humans' anthropomorphisms begin to be deconstructed.

The social behavior patterns detailed here will be familiar to students of developmental psychology: they include many components of successful communication (Bates 1976; Trevarthen 1979; Mandler 1992). 
By extension, it may be that anthropomorphisms occur when an animal's behavior follows some or all of these rules for successful human-human communication. The attributions in anthropomorphism are similar to those which adults make to infants: what Newson (1979) calls "adultomorphism," the interpretation of infants' behavior as intentional, as adult-like.

Anthropomorphized animals demonstrate those features of responsiveness that make early infantcaretaker relationships develop: establishment of visual attention, expressive facial and bodily reaction to the presence of an adult, and contingent body movements (insofar as possible). Just as imitation games ${ }^{3}$ - such as mimicking facial expressions (Meltzoff and Moore 1977)-are implicated in infant development, there is a kind of call-and-response game in the observed dyadic play episodes. The search for the explanation for anthropomorphism, then-and the elaboration of the behavioral components that lead to it-leads to a diagnosis of the pragmatics of social interaction (involving a human and a "humanized" animal). The social categories may be informative in an analysis of what makes an episode of communication work among language-using humans, too.

\section{Physical Prompts to Anthropomorphisms}

An integrated field of anthropomorphism research could also gather a catalogue of purely anatomical prompts to complement its catalogue of behavioral prompts. There exists a small and disparate literature on the physical features which lead to-or, in the case of designed objects, are the result ofanthropomorphizing, which we here collect. Some animals are more likely to be anthropomorphized than others (Eddy, Gallup and Povinelli 1993). Those animals who bear a superficial physical similarity to ourselves_-apes and monkeys—and those who are at least in our taxonomic group—mammals—are the likeliest candidates. (This betrays a Western cultural preference: the Japanese are more favorably disposed to invertebrates, for instance (Kellert 1996).) Furthermore, there are specific characteristics which appear to be associated with an increase in the rate of anthropomorphism. Gould (1979), noticing that the ageless Mickey Mouse had nonetheless transformed markedly over his fifty-year lifespan, observed, after Lorenz, that he had been "juvenalized," that is, neotenized. In particular, Mickey's eyes grew progressively larger (and, though Gould does not comment on it, gained human-like scleras), and the size of his head and cranial vault-the displacement of the front of the ear from the nose as a ratio of the length of the face-increased. In other words, he was made to look more childlike. The salience of these features is corroborated by Hinde and Barden (1985), who measured the length of the forehead and snout of teddy bears designed through the twentieth century. Insofar as the "surviving" teddy bears represent those preferred by consumers (and we prefer those bears that we can play with, and we play with those which are like us), one can conclude from their results that longer foreheads and smaller snouts are preferred.

Though he was not concerned with anthropomorphisms per se, Lorenz was in effect speaking about the physical prompts for anthropomorphism in describing the "innate releasing mechanisms" which serve to encourage human adults to nurture their young. By extension, human beings may have redirected feelings of attachment to those non-human animals who exhibit one of the releasers characteristic of juveniles: "[a] relatively large head, predominance of the brain capsule, large and low-lying eyes, bulging cheek region, short and thick extremities, a springy elastic consistency, and clumsy movements" (Lorenz 1950/1971, p. 135). This "cute response" may be further encouraged by traits which increase the seeming "cuddliness" of an animal: fur, fuzziness, and softness of skin or hair. Even dogs may "anthropomorphize" furry creatures: in a study of the interactions of dogs and dog-like robots, the dogs only treated the robots covered in fur as social partners (Kubinyi et al. 2004). This has been termed "dogomorphism" (Bekoff 2005) or canine-morphizing (Caporael and Heyes 1997). Societal perception and valuation of endangered species is determined at least in part by the animals' physical characteristics: humans value "large attractive animals with an erect bearing," and "animals that walk, run, or fly rather than crawl, slither, or 
live underground" (Kellert 1996, p. 102). (Asquith [1997] notes, though, that ideas about the defining characteristics of humanness differ greatly by culture.) An individual's familiarity with or exposure to the animal, the species' degree of evolutionary and anatomical relatedness to Homo sapiens (Eddy, Gallup and Povinelli 1993; Bekoff 2004), as well as our own species' powers of pattern-finding (Guthrie 1997) have all been implicated (Mitchell and Hamm 1996).

Endangered or threatened species whose members are big-eyed, fuzzy, or large elicit more attention and concern than small-eyed, slimy, or tiny animals. The most popular and protected species are "aesthetically appealing" and have familiar, identifiable features (Kellert 1996). To these we suggest adding the following features and simple movements, many of which are typical of domestic dogs: large round eyes (especially with distinct irises); a discernable mouth, ears, and nose; the ability to raise the mouth at its edges, approximating a smile; alterable, nonrigid facial features; reactive posturing of the head (enabling the expressive use of the face or head); and the use of limbs on one's face (such as to cover or scratch it).

The design of images or objects intended to evoke animacy contributes further prompts. In designing Kismet, an expressive robotic agent, Breazeal in effect exploited anthropomorphism: her agent "attends" to human-relevant stimuli, and humans tend to respond socially to this attention (Breazeal 2002). Cartoon animators who seek to emulate natural behavior in their characters exaggerate the scale of behaviors in order that the behavior seems lifelike. This is traceable to the Walt Disney Company, whose animations popularized the use of "stretch and squash" to make two-dimensional figures convey the desired affect or personality (Culhane 1988).

A listing of these elements is by no means an exhaustive catalogue of the external prompts of anthropomorphisms; instead, it gives an idea where directed research might begin. Withal, such a listing of mostly anatomical metrics can be complemented by a fuller behavioral unpacking of anthropomorphism. Ultimately, behavioral prompts for anthropomorphism may well trump any physical similarities (Mitchell and Hamm 1996). As Heider and Simmel (1944) showed, humans readily and consistently anthropomorphize even geometric figures, dependent largely on the temporal relationship of the shapes' movements. Specifying all the behaviors which prompt anthropomorphisms is a large and fertile field.

\section{Discussion}

But man himself cannot express love and humility by external signs, so plainly as does a dog, when with drooping ears, hanging lips, flexuous body, and wagging tail, he meets his beloved master (Darwin 1872/1965, p. 10).

Broadly, anthropomorphism is the attribution of human characteristics to non-human creatures and inanimate objects. Inanimate objects are made familiar through physical personification (human faces in the moon and mountains; an old couch which collapses at the knees; treacherous vines reaching spindly arms to snag passersby) or assigning of personality traits (a tired and vengeful computer; the yearning of a lost mitten to be reunited with its match; disagreeable cell phones; intransigent jar lids). Natural phenomena and gods were anthropomorphized in various ancient societies: "(w)inds were angry or gentle, floods...were living beings with their own names and personalities, and animals were seen as an incarnation of human spirits" (Frankfort et al. 1967, p. 12). We have been concerned primarily with anthropomorphisms of non-human animals. Contemporary language use is especially rife with these attributions-as toward the pet who understands, supports, seeks revenge on, tricks, or loves his owner. 
But the predominant connotation of the word itself is pejorative: a cry of "anthropomorphism!" is an accusation. It implies a misattribution of human-like abilities-especially mental abilities—to non-humans (Sober 2005). There is an ongoing debate among scientists about the merits or harm of anthropomorphisms. (A more complete discussion of the various dimensions and applications of the term, and its waxing and waning popularity, can be found elsewhere [see, e.g., Mitchell, Thompson and Miles 1997; Daston and Mitman 2005].) To those in the latter camp, using anthropomorphisms in the study of animal behavior is "dangerous," an "incubus" from which the field must "struggle to free itself" (Kennedy 1992); an "incurable disease," having "no place in a scientific study" (Kennedy 1992); uncritical, naive, and sloppy (summarized by, e.g., Burghardt 1985; Fisher 1996; Mitchell, Thompson and Miles 1997; Crist 1999); and the recent resurgence in such attributions "risks bringing back the dirty bathwater as we rescue the baby" (Wynne 2004).

Many scientists working with animals in the field come out on the other side. There is a heuristic value of a kind of mock anthropomorphism, primatologists Cheney and Seyfarth claim: it works in helping to predict animal behavior (Kennedy 1992). De Waal (1997) concurs: it helps to make behavior more predictable. Bekoff (2000) offers the notion of "biocentric anthropomorphism" that stresses taking the animals' point of view rather than dismissing it. There is also room for a so-called "critical anthropomorphism" which can be used to formulate hypotheses for acceptable scientific research (Burghardt 1985, 2004). The very discipline of cognitive ethology, which allows that animals have mental experiences which affect their behavior and help to explain it, is in some sense defined by, and reifies, anthropomorphism as scientifically useful (Mitchell 2005). At worst, defenders argue, the use of one's own intuition about the experience of the animal is inevitable (Bekoff 2002), an "involuntary perceptual strategy" (Guthrie 1997); to deny this, they suggest, is "sterile and dull" (Burghardt 1985).

Whether considered a bane or a boon to scientific inquiry, anthropomorphism has undeniably endured. The prevalence of concerns about the plague of anthropomorphism in the last century itself provides evidence that anthropomorphism has regularly played a role in scientific and lay thinking. Darwin's language aligned human and animal experiences in a way that has since come to be identified as squarely anthropomorphic. (Unlike many more cautious scientists since, Darwin did not scare-quote his use of those terms generally considered exclusively human or subjective.) Similarly, Romanes readily attributed puzzlement to caterpillars, jealousy to fish, and imagination to crustaceans (Romanes 1883; Knoll 1997). In an interesting variant on the burgeoning interest in animal protection in today's society (Wise 2002), explicit anthropomorphism could be found in the legal statutes and trial records of the Middle Ages. At this time in history animals were sufficiently anthropomorphized as to be tried and punished (often by death) for all manner of infractions and trespasses against humans and human property, from thievery to felonious intent and "murder" (Evans 2000).

\section{Doing What Comes Naturally}

So why is anthropomorphizing so enduringly popular? Mithen (1996) suggests that the beginnings of anthropomorphic thinking can be dated to 40,000 years ago, in Paleolithic art representing a conversion from totemic representation - of humans in animal form - to the inverse. The ability to anthropomorphize may have allowed early hunters to better predict the behavior of their prey: a flexibility that eventually leads to the development of the modern human brain (Mithen 1996). Related to this, Fisher (1996) suggests that there may be an evolutionary explanation for our tendency to anthropomorphize, consistent with the Lorenz and Gould models. Our drive to affection for a cuddly, purring cat, for instance, may be a biological side effect of our innate drive to care for our (cuddly, cooing) young. This theory connects the notion of innateness with the notion of inevitability. Considered as a perceptual strategy which highlights those things relevant to our survival, anthropomorphism might be considered a product of natural selection, a "tentative adaptation" to our environment (Popper 1972; Guthrie 1997). We, in turn, have 
been shaped by natural selection to view the behavior of other animals in this way (Humphrey 1983). (Recent evidence suggests, in fact, how this selection might map to the brain: Heberlein and Adolphs [2004] found that an individual with bilateral amygdala lesions did not anthropomorphize in contexts where normal controls did.)

Given its persistence, treatment of anthropomorphism as a category error may itself be an error (Fisher 1996; Mitchell 2005): an anthropomorphic statement's appropriateness turns on its utility or correctness, which is an empirical question. We can interpret research in cognitive ethology as accumulating this sort of empirical data on purposes, feelings, motivations, and cognition (e.g., Ristau 1991; Bekoff, Allen and Burghardt 2002; Bekoff 2006). The study of human or nonhuman behavior may profit from beginning a dialogue which has less to do with the perceived merits or demerits of anthropomorphism and instead uses the existence of anthropomorphism as informative about the nature of our social perception.

\section{Anthropomorphism is Dead, Long Live Anthropomorphism}

The powerful human tendency to assign human qualities to animals such as our pets has yet to be the subject of systematic inquiry. Hebb suggested that an objective analysis of the basis of anthropomorphism might make it "suitable for the purposes of a scientific comparative psychology" (1946, p. 88). We have demonstrated a method for such analysis. In addition, the behavioral and physical correlates of anthropomorphism listed herein could be immediately used to inform current research. In particular, the design of "animated" robots intended to interact with humans as pets may benefit from this analysis. A common strategy in robotic design has been to observe and model in rough outline human (or other animal) behavior (Dautenhahn et al. 2002). Instead, one might look specifically at the social categories implicated in anthropomorphisms (Persson, Laaksolahti and Lönnqvist 2000; Duffy 2003). Through the lens of anthropomorphism, we can see that there are definable subsets of animal behavior which lead us to confer human qualities onto some animals. Insofar as robotics designers are interested in the ascription of human-like animacy to their products, the described social categories give new guidelines. As with Kismet, the most successful design of a robot like Aibo may incorporate a subset of key social behavior patterns rather than attempt a thorough reproduction of behaviors of animate creatures. Robot designers may benefit from capturing those behavioral and anatomical features that lead humans to perceive an animal or inanimate object as familiar, as importantly like them.

\section{Looking at Dogs, Seeing Ourselves}

Successful human-dog dyadic play-as marked by human anthropomorphisms of their playmatesreveals consistent patterns, grouped into four kinds of social behavior. The examination of the data of the play behaviors gives occasion to explore the question "what prompts us to anthropomorphize?" Each category arises, too, in successful human-human dialogues. By marking the visible elements of animals to which we attend, we begin to address what makes at least one animal that we anthropomorphize so successful at living with us. A study designed specifically to find markers of particular anthropomorphisms could use the ethological method to match behaviors to particular assertions. Such a study is the natural next step.

Domestic dogs may be a particularly good animal for the study of anthropomorphisms, as recent evidence supports the speculation that domestication has produced a species unusually adept at interpreting and producing signals salient to humans (Hare and Tomasello 1999; Horowitz 2002; Miklósi, Topál and Csányi 2004). The observed, successful bouts of human-dog play represent, in effect, brief dialogues between humans and their anthropomorphized companions; anthropomorphism is the explanatory lubrication, which these dialogues require, between visible behaviors and the seemingly inaccessible internal states of the animal. Anthropomorphizing thus is involved in perpetuating a satisfying 
pet relationship (Serpell 2003). That the attributions have endured can begin to be explained by a more thorough exploration of the behavior of anthropomorphisms. Anthropomorphisms are not complete descriptions of the lives of the animals-nor are they completely accurate; yet the invariability of certain descriptions may betoken more than previously considered. Insofar as an anthropomorphic account is an "intelligible and practical guide to behavior," as Hebb noted more than a half-century ago (1946, p. 88), it is worthy of scientific scrutiny.

\section{Acknowledgements}

Thanks are due to Javier Movellan at the Machine Perception Lab at the University of California, San Diego, with whom the research on the Sony robot "Aibo" was developed. Thanks also to two anonymous referees for thoughtful and helpful comments on earlier versions of this manuscript.

\section{Notes}

1. For other Aibo study results, please contact A. Horowitz; see also Horowitz (2002).

2. This notion is partially modeled on Newson's "contingent reactivity" (1979, p. 208).

3. Whether this is true imitation, emulation, mimicry, or another gradation on the continuum of copying or matching behavior patterns, is a question well addressed by other authors (see, e.g., Whiten and Ham 1992; Horowitz 2003; and references therein). The distinction, while important, is not directly relevant to our present inquiry.

\section{References}

Asquith, P. J. 1984. The inevitability and utility of anthropomorphism in description of primate behaviour. In The Meaning of Primate Signals, 138-176, ed. R. Harrè and V. Reynolds. Cambridge: Cambridge University Press.

Asquith, P. J. 1997. Why anthropomorphism is not metaphor: Crossing concepts and cultures in animal behavior studies. In Anthropomorphism, Anecdotes, and Animals, 22-34, ed. R. W. Mitchell, N. S. Thompson and H. L. Miles. Albany, NY: State University of New York Press.

Bates, E. 1976. Language and Context: The Acquisition of Pragmatics. New York: Academic Press.

Bekoff, M. 1972. The development of social interaction, play, and meta-communication in mammals: An ethological perspective. Quarterly Review of Biology 47: 412-434.

Bekoff, M. 2000. Animal emotions: Exploring passionate natures. BioScience 50: 861-870.

Bekoff, M. 2002. Minding Animals: Awareness, Emotion, and Heart. New York: Oxford University Press.

Bekoff, M. 2004. Wild justice and fair play: cooperation, forgiveness, and morality in animals. Biology \& Philosophy 19: 489-520.

Bekoff, M. 2005. The question of animal emotions: An ethological perspective. In Mental Health and Wellbeing in Animals, 15-27, ed. F. McMillan. Ames, IA: lowa State University Press.

Bekoff, M. 2006. Animal Passions and Beastly Virtues: Reflections on Redecorating Nature. Philadelphia: Temple University Press.

Bekoff, M., Allen, C. and Burghardt, G. M. eds. 2002. The Cognitive Animal: Empirical and Theoretical Perspectives on Animal Cognition. Cambridge, MA: MIT Press.

Bekoff, M. and Byers, J. eds. 1998. Animal Play: Evolutionary, Comparative, and Ecological Perspectives. Cambridge: Cambridge University Press.

Berry, D. S., Misovich, S. J., Kean, K. J. and Baron, R. M. 1992. Effects of disruption of structure and motion on perceptions of social causality. Personality and Social Psychology Bulletin 18: 237244.

Breazeal, C. L. 2002. Designing Sociable Robots. Cambridge, MA: MIT Press. 
Burghardt, G. M. 1985. Animal awareness: Current perceptions and historical perspective. American Psychologist 40: 905-919.

Burghardt, G. M. 2004. Ground rules for dealing with anthropomorphism. Nature 430: 15.

Caporael, L. R. and Heyes, C. M. 1997. Why anthropomorphize? Folk psychology and other stories. In Anthropomorphism, Anecdotes, and Animals, 59-73, ed. R. W. Mitchell, N. S. Thompson and H. L. Miles. Albany, NY: State University of New York Press.

Crist, E. 1999. Images of Animals: Anthropomorphism and Animal Mind. Philadelphia: Temple University Press.

Culhane, S. 1988. Animation: From Script to Screen. New York: St. Martin's Press.

Darwin, C. 1965. The Expression of the Emotions in Man and Animals. Chicago: The University of Chicago Press. (Original work published 1872)

Daston, L. and Mitman, G. eds. 2005. Thinking with Animals: New Perspectives on Anthropomorphism. New York: Columbia University Press.

Dautenhahn, K., Bond, A. H., Cañamero, L. and Edmonds, B. eds. 2002. Socially Intelligent Agents: Creating Relationships with Computers and Robots. Norwell, MA: Kluwer Academic Publishers.

de Waal, F. B. M. 1997. Foreword. In Anthropomorphism, Anecdotes, and Animals, xiii-xvii, ed. R. W. Mitchell, N. S. Thompson and H. L. Miles. Albany, NY: State University New York Press.

Duffy, B. R. 2003. Anthropomorphism and the social robot. Robotics and Autonomous Systems 42: 177190.

Eddy, T. J., Gallup, G. G., Jr. and Povinelli, D. J. 1993. Attribution of cognitive states to animals: Anthropomorphism in comparative perspective. Journal of Social Issues 49: 87-101.

Evans, E. P. 2000. The Criminal Prosecution and Capital Punishment of Animals. Union, NJ: The Lawbook Exchange, Ltd. (Original work published 1906)

Fagen, R. 1981. Animal Play Behavior. New York: Oxford University Press.

Fisher, J. A. 1996. The myth of anthropomorphism. In Readings in Animal Cognition, 3-16, ed. M. Bekoff and D. Jamieson. Cambridge, MA: MIT Press.

Frankfort, H., Frankfort, H. A., Wilson, J. A. and Jacobsen, T. 1967. Before Philosophy: The Intellectual Adventure of Ancient Man: An Essay on Speculative Thought in the Ancient Near East. Baltimore, MD: Penguin Books.

Garvey, C. 1976. Some properties of social play. In Play-Its Role in Development and Evolution, 570583, ed. J. Bruner, A. Jolly and K. Sylva. New York: Basic Books, Inc.

Gould, S. J. 1979. Mickey Mouse meets Konrad Lorenz. Natural History 88: 30-36.

Guthrie, S. E. 1997. Anthropomorphism: A definition and a theory. In Anthropomorphism, Anecdotes, and Animals, 50-58, ed. R. W. Mitchell, N. S. Thompson and H. L. Miles. Albany, NY: State University New York Press.

Hare, B. and Tomasello, M. 1999. Domestic dogs (Canis familiaris) use human and conspecific social cues to locate hidden food. Journal of Comparative Psychology 113: 173-177.

Hebb, D. O. 1946. Emotion in man and animal: An analysis of the intuitive process of recognition. Psychological Review 53: 88-106.

Heberlein, A. S. and Adolphs, R. 2004. Impaired spontaneous anthropomorphizing despite intact perception and social knowledge. Proceedings of the National Academy of Sciences 101(19): 7487-7491.

Heider, F. and Simmel, M. 1944. An experimental study of apparent behavior. The American Journal of Psychology 57: 243-259.

Hinde, R. A. and Barden, L. A. 1985. The evolution of the teddy bear. Animal Behaviour 33: 1371-1373.

Horowitz, A. C. 2002. The behaviors of theories of mind, and a case study of dogs at play. Ph.D. thesis. University of California, San Diego.

Horowitz, A. C. 2003. Do humans ape? Or do apes human? Imitation and intention in humans (Homo sapiens) and other animals. Journal of Comparative Psychology 117(3): 325-336. 
Horowitz, A. C. 2004. The mind of a dog in play. In Encyclopedia of Animal Behavior, 835-836, ed. M. Bekoff. Westport, CT: Greenwood Press.

Humphrey, N. 1983. The adaptiveness of mentalism? Behavioral \& Brain Sciences 6: 366.

Irvine, L. 2004. If You Tame Me: Understanding our Connection to Animals. Philadelphia: Temple University Press.

Ishiguro, H. 2003. Communication robots. Paper presented at DIMI Workshop "Perceptive Social Agents and Robots," La Jolla, CA, 9-10 January, 2003.

Kellert, S. R. 1996. The Value of Life: Biological Diversity and Human Society. Washington, DC: Island Press.

Kennedy, J. S. 1992. The New Anthropomorphism. Cambridge: Cambridge University Press.

Knoll, E. 1997. Dogs, Darwinism, and English sensibilities. In Anthropomorphism, Anecdotes, and Animals, 12-21, ed. R. W. Mitchell, N. S. Thompson and H. L. Miles. Albany, NY: State University of New York Press.

Kubinyi, E., Miklósi, A., Kaplan, F., Gácsi, M., Topál, J. and Csányi, V. 2004. Social behaviour of dogs encountering AIBO, an animal-like robot in a neutral and in a feeding situation. Behavioural Processes 65: 231-239.

Lorenz, K. 1950. Ganzheit und Teil in der tierischen und menschlichen Gemeinschaft. Reprinted in Studies in Animal and Human Behaviour, 1971, vol. 2, 115-195, ed. R. Martin. Cambridge, MA: Harvard University Press.

Mandler, J. M. 1992. How to build a baby: II. Conceptual primitives. Psychological Review 99: 587-604.

Meltzoff, A. N. and Moore, M. K. 1977. Imitation of facial and manual gestures by human neonates. Science 198: 75-78.

Miklósi, A., Topál, J. and Csányi, V. 2004. Comparative social cognition: What can dogs teach us? Animal Behaviour 67: 995-1004.

Mitchell, R. W. and Hamm, M. 1996. The interpretation of animal psychology: Anthropomorphism or behavior reading? Behaviour 134: 173-204.

Mitchell, R. W. and Thompson, N. S. eds. 1986a. Deception: Perspectives on Human and Nonhuman Deceit. Albany, NY: State University of New York Press.

Mitchell, R. W. and Thompson, N. S. 1986b. Deception in play between dogs and people. In Deception: Perspectives on Human and Nonhuman Deceit, 193-204, ed. R. W. Mitchell and N. S. Thompson. Albany, NY: State University of New York Press.

Mitchell, R. W. and Thompson, N. S. 1991. Projects, routines and enticements in dog-human play. In Perspectives in Ethology. Vol. 9, 189-216, ed. P. P. G. Bateson and P. H. Klopfer. New York: Plenum Press.

Mitchell, R. W., Thompson, N. S. and Miles, H. L. eds. 1997. Anthropomorphism, Anecdotes, and Animals. Albany, NY: State University of New York Press.

Mitchell, S. D. 2005. Anthropomorphism and cross-species modeling. In Thinking with Animals: New Perspectives on Anthropomorphism, 100-117, ed. L. Daston and G. Mitman. New York: Columbia University Press.

Mithen, S. 1996. The Prehistory of the Mind: The Cognitive Origins of Art, Religion and Science. London: Thames and Hudson Ltd.

Morris, P., Fidler, M. and Costall, A. 2000. Beyond anecdotes: An empirical study of "anthropomorphism." Society \& Animals 8(2): 151-165.

Newson, J. 1979. The growth of shared understandings between infant and caregiver. In Before Speech: The Beginning of Interpersonal Communication, 207-222, ed. M. Bullowa. London: Cambridge University Press.

Persson, P., Laaksolahti, J. and Lönnqvist, P. 2000. Stereotyping characters: A way of triggering anthropomorphism? In Proceedings of Socially Intelligent Agents-The Human in the Loop (Fall AAAI Symposium). 
Podberscek, A. L., Paul, E. S. and Serpell, J. A. eds. 2000. Companion Animals and Us: Exploring the Relationships between People and Pets. Cambridge: Cambridge University Press.

Popper, K. 1972. Objective Knowledge: An Evolutionary Approach. Oxford: Oxford University Press.

Ristau, C. ed. 1991. Cognitive Ethology: The Minds of Other Animals. Hillsdale, NJ: Lawrence Erlbaum.

Romanes, G. J. 1883. Mental Evolution in Animals. London: Keegan Paul, Trench \& Co.

Rooney, N. J., Bradshaw, J. W. S. and Robinson, I. H. 2001. Do dogs respond to play signals given by humans? Animal Behaviour 61: 715-722.

Sanders, C. R. 1999. Understanding Dogs: Living and Working with Canine Companions. Philadelphia: Temple University Press.

Serpell, J. A. 2003. Anthropomorphism and anthropomorphic selection-beyond the "cute response." Society \& Animals 11: 83-100.

Sober, E. 2005. Comparative psychology meets evolutionary biology: Morgan's canon and cladistic parsimony. In Thinking with Animals: New Perspectives on Anthropomorphism, 85-99, ed. L. Daston and G. Mitman. New York: Columbia University Press.

Sony entertainment robot Aibo operating instructions 2000. [Brochure]. Japan: Sony Corporation.

Tomasello, M., Call, J., Nagell, K., Olguin, R. and Carpenter, M. 1994. The learning and use of gestural signals by young chimpanzees: A trans-generational study. Primates 35: 137-154.

Trevarthen, C. 1979. Instincts for human understanding and for cultural cooperation: Their development in infancy. In Human Ethology: Claims and Limits of a New Discipline, 530-571, ed. M. von Cranach, K. Foppa, W. Lepenies and D. Ploog. New York: Cambridge University Press.

U.S. pet ownership statistics 2006. Humane Society of the United States. Available from: <http://www.hsus.org/pets/issues_affecting_our_pets/pet_overpopulation_and_ownership_statisti cs/us_pet_ownership_statistics.html > Accessed 3 March, 2006.

Whiten, A. and Ham, R. 1992. On the nature and evolution of imitation in the animal kingdom: Reappraisal of a century of research. In Advances in the Study of Behavior, 239-283, ed. P. J. B. Slater, J. S. Rosenblatt, C. Beer and M. Milinski. San Diego, CA: Academic Press.

Wise, S. 2002. Drawing the Line: Science and the Case for Animal Rights. Cambridge, MA: Perseus Publishing.

Wynne, C. D. L. 2004. The perils of anthropomorphism. Nature 428: 606. 